\title{
As juventudes na mídia durante a pandemia de covid-19: compreender para educar
}

\author{
Daniel Machado Da Conceição ${ }^{1}$ \\ Cristiano Mezzaroba ${ }^{2}$ \\ Marcos Rogério dos Santos ${ }^{3}$
}

\begin{abstract}
Resumo:
A pandemia de covid-19 impôs uma nova ordem, um outro ritmo para a humanidade, alterando a percepção de tempo, de estabilidade, motivando a construção de novos ritmos e formas de olhar e refletir sobre os mais diversos âmbitos de nossas vidas. São inúmeras as questões que o desdobramento da pandemia vai desvelando, mas tem um fator que chama atenção diante desse cenário atual: o comportamento dos jovens. Se por um lado, o senso comum associa os jovens a seres desprovidos de responsabilidade individual e coletiva, por outro, o sistema midiático costuma veicular informações de diferentes ordens sobre a juventude (do senso comum até questões mais críticas e amplas). Sendo assim, acreditamos que seria pertinente, para a prática e reflexão educativa, analisarmos alguns dos discursos que têm associado o fenômeno da pandemia e juventude. A proposta configurou-se como um exercício sociológico e foi construída a partir de recortes jornalísticos escolhidos aleatoriamente em diferentes portais de notícias da internet que ao longo da pandemia e até janeiro de 2021, evidenciam formas plurais de tratar, representar e fazer pensar sobre os jovens brasileiros, auxiliando àqueles que atuam no contexto educativo a compreendê-los melhor.
\end{abstract}

\section{Palavras-chave:}

Sociologia da Juventude. Pandemia. Portais de informação. Educação.

\section{Youth in the media during the covid-19 pandemic: understand to educate}

\footnotetext{
Abstract: The covid-19 pandemic imposed a new order, another rhythm for humanity, changing the perception of time, of stability, motivating the construction of new rhythms and ways of looking and reflecting on the most diverse areas of our lives. There are countless issues that the development of the pandemic unveils, but there is a factor that draws attention in the face of this current scenario: the

1 Doutorando do Programa de Pós-Graduação em Educação (UFSC). Bolsista do Programa de Bolsas Universitárias de Santa Catarina. E-mail: danielmdac1@gmail.com. ORCID iD: http://orcid.org/0000-0002-6065-6656.

2 Doutor em Educação, professor do Departamento de Educação Física da Universidade Federal de Sergipe e do Programa de Pós-Graduação em Educação (PPGED/UFS). E-mail: cmezzaroba@academico.ufs.br. ORCID iD: http://orcid.org/0000-0003-4214-0629. 3 Doutor em Educação, integra o Núcleo Interdisciplinar em Políticas Públicas (NIPP/UFSC). E-mail: marcosparana110@gmail.com. ORCID iD: https://orcid.org/0000-0002-0736-8671.
} 
behavior of young people. If, on the one hand, common sense associates young people with beings who do not have individual and collective responsibility, on the other hand, the media system usually conveys information of different orders about youth (from common sense to more critical and broader issues). Therefore, we believe that it would be pertinent, for educational practice and reflection, to analyze some of the speeches that have associated the phenomenon of the pandemic and youth. The proposal was configured as a sociological exercise and was built from journalistic cuts chosen randomly in different internet news portals that throughout the pandemic and until January 2021, show plural ways of treating, representing and making people think about young Brazilians, helping those who work in the educational context to understand them better.

Keywords: Sociology of Youth. Pandemic. Information portals. Education.

\section{La juventud en los medios durante la pandemia de covid-19: entender para educar}

Resumen: La pandemia covid-19 impuso un nuevo orden, otro ritmo para la humanidad, cambiando la percepción del tiempo, de la estabilidad, motivando la construcción de nuevos ritmos y formas de mirar y reflexionar sobre los ámbitos más diversos de nuestra vida. Son innumerables las cuestiones que devela el desarrollo de la pandemia, pero hay un factor que llama la atención ante este escenario actual: el comportamiento de los jóvenes. Si, por un lado, el sentido común asocia a los jóvenes con seres sin responsabilidad individual y colectiva, por otro lado, el sistema mediático suele transmitir información de diferentes órdenes sobre la juventud (desde el sentido común hasta temas más críticos y amplios). Siendo así, creemos que sería pertinente, para la práctica y la reflexión educativa, analizar algunos de los discursos que han asociado el fenómeno de la pandemia y juventud. La propuesta se configuró como un ejercicio sociológico y se construyó a partir de recortes periodísticos elegidos aleatoriamente en diferentes portales de noticias de internet que a lo largo de la pandemia y hasta enero de 2021, muestran formas plurales de tratar, representar y hacer pensar a los jóvenes que atienden a quienes trabajan en el contexto educativo para comprender los mejor.

Palabras clave: Sociologia de la Juventud. Pandemia. Portales de información. Educación.

\section{Introdução}

Desde que a OMS - Organização Mundial da Saúde - decretou o estado de pandemia mundial, em 11 de março de 2020, cuja disseminação de um novo vírus, da grande família dos coronavírus, denominado cientificamente como SARS-Cov-2, popularmente conhecido como covid-19, inicialmente detectado na China em dezembro de 2019 e que rapidamente se disseminou para o restante do mundo, temos experienciado novas (por vezes complexas, muitas vezes difíceis) formas de olhar para os mais diversos âmbitos de nossas vidas.

Com os fluxos da globalização intensificados, não só o novo e enigmático vírus se espalhou rapidamente pelo mundo, graças à própria produção humana com seus meios de transporte ultrarrápidos (os aviões), como também a própria rede comunicacional revela sua ambiguidade neste complexo e problemático cenário do mundo, vivendo uma pandemia: enquanto as mais diversas tecnologias digitais de informação e comunicação proporcionam ao campo científico, por exemplo, trocas de informações que outrora demorariam dias ou semanas; ou mesmo que sejamos informados diuturnamente pela grande mídia mundial sobre as novidades quanto à doença, cuidados que devemos ter etc., também somos impactados por uma avalanche de notícias falsas ${ }^{1}$ que misturam

1 As conhecidas fake news. Sobre isso, em especial quanto às questões pertinentes às notícias falsas na pandemia de covid-19, ver Santos et al. (2020). 
ideologias (como, por exemplo, a nacionalização das vacinas - como a "vacina chinesa" sendo algo perigoso pelo vírus ter sido oriundo, pelo que se sabe, da China nos meses finais de 2019), obscurantismo $^{2}$ (como certas narrativas de teor religioso se sobrepondo, institucionalmente, sobre os discursos e práticas científicas), negacionismo ${ }^{3}$ (que se revela a partir de um conjunto de fatores com seus múltiplos interesses, passando pelo outro fator que chama atenção diante desse quadro atual, que se refere ao comportamento dos jovens durante a pandemia.

Se dentre tantas questões que a pandemia vai nos trazendo para serem desveladas no nosso dia a dia, como, por exemplo, o peso das desigualdades sociais impactando determinados nichos populacionais em que aparece a interseccionalidade que envolve classe social, etnia e gênero; passando pela evidência empírica de que os mais acometidos pelo estado mais destrutivo do vírus são os idosos (biologicamente explicado pela imunidade mais baixa conforme aumenta a faixa etária), o que também revela um grave problema das sociedades atuais, que é o descaso com aqueles que deveriam ser mais cuidados e preservados; há outro fator que chama atenção diante desse quadro atual, que se refere ao comportamento dos jovens durante a pandemia.

O senso comum - ou um primeiro e viciado olhar - costuma tratar os jovens como seres desprovidos de responsabilidade individual e coletiva; ou mesmo, como sujeitos cujo interesse se revela de maneira simplista vinculada a um hedonismo geracional. Entretanto, quando observamos com mais atenção e sob as "lentes" da Sociologia da Juventude ${ }^{4}$ esse fenômeno da pandemia e das juventudes (os estigmas sobre os jovens, o senso comum que é produzido e circulado quanto a essa categoria social), somos levados a refletir em relação a como certas representações são criadas, legitimadas e reproduzidas, principalmente quanto ao papel que a mídia tem nas sociedades modernas (SAVAGE, 2009), no sentido de identificar mecanismos discursivos superficiais que tendem a culpabilizar os jovens quando, no fundo, ao observarmos as condições estruturais e contextuais, visualizamos neles também vítimas de um sistema que não oferece uma atenção maior, uma oferta educacional e formativa digna e ampla, de longa duração, que implica, também, na dificuldade de acesso e realização profissional, situações que expressam sua condição ${ }^{5}$ juvenil.

Assim, neste ensaio, refletiremos e analisaremos, a partir de recortes aleatórios com matérias jornalísticas de vários portais de informação brasileiros (EBC - Agência Brasil; G1 (Grupo Globo); Portal IG; GZH - Gaúcha Zero Hora; O Globo; UOL; El País Brasil) que estão disponíveis de modo facilitado na rede mundial de computadores e que acessamos diariamente, os quais vão trazendo o contexto do jovem na pandemia e questões como comportamento, família, relações, escola/ universidade, mundo do trabalho, perspectiva de futuro etc., que apresentam a situação ${ }^{6}$ juvenil.

A identificação e seleção dos materiais jornalísticos presentes em nosso estudo ocorreu de forma aleatória, pois trata-se de endereços eletrônicos que os autores costumam acessar para leituras diárias, o que evidencia a produção e circulação de materiais sobre a temática jovem enquanto centralidade também no período de pandemia. A partir da identificação e captura desse material jornalístico e análise da sua relevância, selecionamos textos que tratam da sociabilidade, educação, trabalho, protagonismo e ação social dos jovens durante a pandemia, temas mediados pelos grupos

\footnotetext{
2 Ver mais sobre o assunto no link: https://www12.senado.leg.br/noticias/infomaterias/2020/06/combate-a-epidemias-e-luta-secular-contra-obscurantismo-e-interesses-politicos. Acesso em: 17 jan. 2021.

3 Mais informações sobre isso no site: http://adunicamp.org.br/novosite/negacao-da-ciencia-cresce-no-brasil-e-e-uma-ameaca-em-tempos-de-pandemia/. Acesso em: 17 jan. 2021.

4 Furter (1975); Groppo (2000, 2016, 2017); Groppo e Silveira (2020); Pais (2001); Almeida e Eugênio (2006); Savage (2009); Bauman (2013); Weisheimer et al. (2013); Foracchi (2018); Bourdieu (1983); Dayrell (2003).

5 "A condição juvenil corresponde ao modo como a sociedade atribui significados às juventudes em determinadas estruturas sociais, históricas e culturais. Dessa maneira, busca-se destacar que, mais do que faixa etária, a condição juvenil é uma posição na hierarquia social. No caso dos jovens, uma posição subordinada aos adultos" (WEISHEIMER et al., 2013, p. 25).

6 “A situação juvenil diz respeito aos diversos percursos experimentados pela condição juvenil, ou seja, traduz as suas diversas configurações. Esta última categoria é utilizada então para se referir aos variados processos empíricos, condições conjunturais e particularizadas das múltiplas juventudes" (WEISHEIMER et al., 2013, p. 26).
} 
familiares, entre outros, cuja intenção foi ensaiar sociologicamente quanto às relações possíveis com os elementos teóricos pertinentes ao campo da Sociologia da Juventude.

O presente trabalho se justifica pelo intento de compreender o tempo em que vivemos, pela situação singular e difícil que todos os países vêm enfrentando há um ano, em especial, no sentido de compreender a categoria social juventude e as narrativas midiáticas que são criadas e vinculadas aos jovens, porque entendemos que deveríamos nos aproximar de seus contextos para compreendermos mais quais possibilidades educativas e formativas temos ou mesmo os motivos das atuais mediações educativas não apresentarem resultados efetivos (em relação às questões de conscientização e de cuidados sanitários) em relação à pandemia.

Para uma melhor organização e compreensão das informações apresentadas, o texto foi dividido em quatro partes. A divisão teve por objetivo manter a linearidade (ciclo de fases sucessivas) das etapas anteriores, onde cada parte predecessora tem por finalidade auxiliar na compreensão da etapa posterior. Seguindo esta ordem, inicialmente apresentaremos uma breve introdução para situar o leitor da importância da construção desse texto, posteriormente apresentaremos algumas concepções teóricos sobre o tema que envolve juventude e sua pluralidade. A terceira parte visa apresentar o que foi levantado com a realização da captura dos recortes jornalísticos (dos portais de informação on-line) e as relações possíveis com os elementos teóricos pertinentes ao campo da Sociologia da Juventude. Por fim, a última parte tem por objetivo apresentar as considerações finais.

\section{A Sociologia da Juventude ampliando compreensões}

Quando nos referimos ao termo "juventude", na maioria das vezes - o que se reforça pelo próprio senso comum - o primeiro significado que nos vêm à mente é uma compreensão exclusivamente pautada por geração e faixa etária que também significa estar/pertencer a uma etapa da vida, uma fase intermediária pós-infância e pré-vida adulta.

Pensar a juventude para além dessa restrição a uma determinada faixa etária, compreendendo-a com suas particularidades, singularidades e complexidades, exige, de antemão, tratá-la sua pluralidade de contextos e dimensões, portanto, pensar as juventudes (assim, no plural).

Configura-se um exercício sociológico e antropológico de tratar tal temática como uma importante categoria social (BOURDIEU, 1983; KEHL, 2003), algo que envolve contextos diversos e plurais de seus sujeitos - que não se consideram mais crianças, mas também não são vistos pela sociedade como adultos - e que são condicionados por elementos históricos, políticos, econômicos, sociais, culturais, geracionais, étnicos etc.

Nos últimos tempos a juventude tem sido foco de uma série de reflexões que se esforçam para compreendê-la em suas diferentes dimensões. Dentre os campos de expertise que se ocupam dessa temática, a Sociologia empreende um amplo esforço analítico visando desnaturalizar a ideia reducionista de juventude pautada apenas pelo prisma etário que vinculado a abordagens biológicas (puberdade - concepção da medicina; comportamental e personalidade - concepção atribuída à pedagogia e psicologia), desconsideram em maior ou menor grau os impactos de condicionantes sociais e mesmo do momento histórico. Logo, compreender os jovens e juventudes como categorias sociais permite identificar como resultado de uma construção social. Por essa razão, Bourdieu (1983) pode afirmar que juventude é apenas uma palavra ao observar que discursos e narrativas definem o lugar de jovens e o lugar de velhos na sociedade.

A magnitude da noção sociológica da juventude ganhou relevância, pois nela, se entrelaçam intersecções, questões de classe social, gênero, trabalho, educação, uso de tecnologias, etnia, religião, cultura, identidade e outros marcadores sociais que permeiam o cotidiano dos jovens. Perspectiva que se materializa em cenários marcados por diferentes desigualdades sociais, mais evidente ainda em países como um Brasil repleto de brasis (RIBEIRO, 2006). 
Portanto, a noção de juventude é marcada por uma pluralidade de fatores, o que implica na existência de juventudes no plural, que ocupam diferentes tempos e lugares, permitindo ser identificada como mais que uma palavra (MARGULIS; URRESTI, 1996). "Colocar juventude no plural expressa a posição de que é necessário qualificá-la, percebendo-a como uma complexa e heterogênea, na busca de evitar simplificações e esquematismos" (VELHO, 2006, p. 192). Assim, ser jovem e pertencer às camadas menos abastadas é vivenciar não apenas uma luta por sobrevivência, mas uma "[...] luta simbólica pelo reconhecimento, pelo acesso a um ser social socialmente reconhecido, ou seja, numa palavra, à humanidade" (BOURDIEU, 2007, p. 295). A condição de reconhecimento é o que assegura a possibilidade de continuar existindo, de ser percebido, de sentir-se pertencente, de ser sujeito de direito e vivenciar a democracia em seus diferentes desdobramentos.

Os estudos sobre juventude ganham notoriedade durante o século XX, desenvolvendo análises a partir da abordagem da geração. Ortega Y Gasset (2005) destaca que uma grande descoberta da sociologia foi identificar que a organização social ao longo da história sempre esteve marcada por questões biológicas, especificamente, idade e sexo. O referido filósofo argumenta que em determinados momentos se pode perceber uma predominância do poder entre épocas masculinas e épocas femininas. O mesmo deslocamento de poder se percebe entre velhos e jovens. O fenômeno da juventude nas primeiras décadas dos anos 1900, instigou Ortega y Gasset a refletir se o modo juventutis iria avançar e perdurar. A preocupação ainda naquele momento envolvia a madureza, presente nos séculos anteriores, mas que naquele momento histórico sinalizava para uma transformação, as vidas privada e pública não estavam sendo moldadas pelo modo de vida adulto. Um novo padrão de valores, comportamentos e atitudes estavam deslocando-se e impactando todas as esferas do social.

O cenário norte-americano que se transformava em ritmo acelerado foi analisado por Savage (2009), que no título da sua obra indica como criação da juventude, um processo que tinha mais dúvidas sobre sua permanência e impactos na sociedade moderna. Os padrões de juventude passam a ser apropriados para o consumo, também ditam novos conceitos e a própria performance, agora, estetizada. Esse modo de ser, postura relacionada a uma vida ativa em Groppo (2000), é reconhecida como juvenilização da sociedade.

Importante perceber que a abordagem apresentada por Ortega y Gasset (2005), Savage (2009) e Groppo (2000), observam a juventude a partir das disputas e conflitos de geração. O conceito de socialização, em sua leitura mais generalista, indica ser um processo no qual as gerações mais novas aprendem com as gerações mais velhas/antigas. O objetivo é a transmissão de valores, saberes e conhecimentos para manutenção da reprodução social. Os conflitos geracionais fazem parte do processo como gerações distintas se relacionam, nem sempre as gerações mais novas aceitam com total passividade as imposições ou o status quo. "É como se uma geração 'cobrasse' à outra a fidelidade ao conjunto de problemas que a marcou como geração" (FORACCHI, 2018, p. 30). Uma recusa em aceitar o modo de "[...] ser adulto, concretizado no arranjo convencional das estruturas institucionais” (FORACCHI, 2018, p. 17).

Os conflitos e tensões ligados à juventude estão relacionados à rebeldia e uma postura crítica da sociedade: "Notemos que não é sem justificativas que os jovens são frequentemente adjetivados como modernos, diferentes, inovadores ou rebeldes" (WEISHEIMER et al., 2013, p. 17). Nesse contexto de geração, a moratória social surge como um momento de transição e de esperança, pois, a juventude significa na sociedade uma dualidade, um elo fraco em razão da sua incipiente inserção e um elo forte pela sua longevidade e energia vital capaz de garantir a reprodução social (MORIN, 2013).

A abordagem geracional é apenas uma das possibilidades de análise sobre a juventude, que tem no recorte etário (faixa etária) observações sobre o momento de transformação e transição entre a infância e vida adulta. A medicina trata da concepção de puberdade identificando as transformações físicas e biológicas que os corpos sofrem. A psicologia e a pedagogia estruturam sua concepção nas transformações de personalidade e comportamental. A concepção sociológica 
indica a juventude como uma fase intermediária entre infância e vida adulta, procurando perceber as implicações decorrentes das interseccionalidades e das transformações históricas e sociais que incidem sobre esse grupo (GROPPO, 2000, 2017).

A abordagem geracional e etária com suas concepções, não conseguem em determinado momento superar estereótipos ou atribuições deterministas aos jovens e à própria juventude. Juventude é uma construção histórica e social, seu reconhecimento como categoria social permite ampliar o escopo para os seus múltiplos sentidos. Fato que reconhece condicionantes sociais, modo de vida dos jovens, expectativas no presente e projeções para vida futura.

As principais abordagens apresentadas fazem parte de discursos e narrativas que envolvem as ações do Estado ao fomentar políticas públicas para juventude e os veículos de mídia se apropriam dos valores e sentidos para disseminar a juvenilização, destacando o espírito jovem que pode e deve ser conquistado, por meio do consumo de produtos e serviços, bem como, da estilização do comportamento jovial. As reportagens selecionadas - como veremos - circulam por essa narrativa, valorizando a condição de ser jovem em determinados momentos, já em outros, depreciam ao alegar imaturidade ou rebeldia.

\section{A mídia pautando "as juventudes" na pandemia}

A mídia, enquanto materialidade (equipamentos e instrumentos tecnológicos), enquanto mercado (empresas comunicacionais que produzem e veiculam informação, entretenimento e publicidade) e enquanto ideologia (com suas simbologias e intencionalidades próprias), tem sido compreendida na modernidade como uma "instituição paradigmática" (como uma instituição cultural, similar ao papel das escolas, universidades, igrejas etc.), nas palavras de Thompson (1998), pois as indústrias de mídia "[...] implicam uma mistura complexa de diferentes tipos de atividades, recursos e poder, ainda que direcionadas essencialmente para a acumulação de determinados recursos e o exercício de certa forma de poder" (THOMPSON, 1998, p. 22).

Ainda segundo Thompson (1998, p. 12),

[...] se quisermos entender a natureza da modernidade - isto é, as características institucionais das sociedades modernas e as condições de vida criadas por elas - devemos dar um lugar central ao desenvolvimento dos meios de comunicação e seu impacto.

Setton (2010) considera que há uma "cultura midiática", e que, ao compreendê-la, podemos compreender a sociedade em que vivemos, com "[...] seus conflitos, lutas internas, jogos de interesses, medos e fantasias" (SETTON, 2010, p. 17). Ainda para tal autora, "[...] a cultura da mídia tem a capacidade de fazer um diagnóstico da história de uma época e de uma sociedade. É um documento histórico. A partir das análises de expressões culturais de nosso tempo, podemos observar posições políticas e ideológicas conflitantes" (SETTON, 2010, p. 27).

Nesse sentido, consideramos que a mídia, termo que embora seja usado no singular, significa a pluralidade dos meios de comunicação (dos mais antigos: rádio, jornal, cinema - aos mais modernos: televisão e internet) e suas mais variadas formas de produção e circulação de produtos culturais, seja em mídia impressa, mídia radiofônica, mídia televisiva e, atualmente, a grande oferta e consumo de mídias digitais, com o advento e intensificação dos usos e potencialidades da internet.

Atentarmo-nos ao que por ela é produzido e circula enquanto cultura de nosso tempo é uma forma de melhor compreender aspectos singulares, como das representações construídas e circulantes no que se referem às culturas juvenis, por exemplo, em épocas como essa, de pandemia mundial, e possibilidades de reflexão quanto aspectos educativos e formativos específicos a essa categoria social. 
Como, então, os jovens foram tratados pela mídia digital (portais de informação brasileiros na internet) durante a pandemia de covid-19 ao longo de 2020 e início de 2021? Que aspectos podem ser destacados, tanto em relação a discursos legitimadores do próprio senso comum, como em relação a discursos mais ampliados e reflexivos no contexto das culturas juvenis em relação à educação e formação?

Ao refletirmos sobre essas questões podemos perceber que a discussão sobre a pandemia envolveu a proteção dos jovens quanto a exposição ao vírus, a mudança no cotidiano escolar e a relação com o saber que atribui duplamente a responsabilidade ao indivíduo (primeiro, como agente do seu aprendizado e, segundo, responsabilizando por seu infortúnio). Enquanto para alguns, o isolamento soou como um privilégio, para outros, ele ampliou o fosso da desigualdade.

A matéria do dia 16 de maio de 2020, Conselho teme efeitos sociais da pandemia entre os jovens, vinculada na Agência Brasil ${ }^{7}$, um mês após as primeiras medidas de isolamento no país, anuncia a preocupação e aponta efeitos devastadores na juventude em relação à educação e ao trabalho. Embora demonstre a preocupação com a parcela mais vulnerável, a imagem presente na reportagem mostra jovens acessando um espaço de formação, em que podemos identificar apenas pessoas brancas. Os jovens das periferias encontram-se em situação de grande vulnerabilidade impossibilitados até mesmo de qualquer deslocamento em cidades com transporte público paralisado (ou mesmo com frota bastante reduzida).

A escolarização necessária para sua formação e qualificação fica adiada, interrompendo para um determinado grupo social os rituais de passagem de conclusão de curso e participação em vestibulares ou mesmo no Exame Nacional do Ensino Médio (ENEM), considerado a porta de acesso dos jovens às universidades públicas. O mais devastador ainda é constatar que os jovens possuem desafios para se inserirem no mundo do trabalho, visando a aquisição de experiência profissional que aumente sua empregabilidade. Também neste aspecto os jovens estão estagnados pela redução e fechamento de vagas de trabalho formais e informais. Situação que prejudica a subsistência e autossuficiência de muitos jovens que contribuem financeiramente para a manutenção de suas famílias ou de seus próprios filhos. Não podemos deixar de registrar que uma das propostas para o pós-pandemia é incentivar os jovens a montarem seus próprios negócios (o falacioso discurso "empreendedor"). Durante o isolamento, o empreendedorismo e sucesso de profissionais que se reinventaram serviu como referência de uma postura corajosa, arrojada, criativa, inovadora e vencedora, embora a própria pandemia evidenciou a corrida de muitos empreendedores solicitando ajuda ao Estado.

O romantismo apregoado ao empreendedorismo exalta o mérito pessoal, enfatizando que mesmo durante um período de incertezas e dificuldades se pode aproveitar oportunidades. Exemplo dessa narrativa encontramos na reportagem Jovens demitidos na pandemia 'se viram nos 30' para pagar as contas, Portal G1 ${ }^{8}$ de Santos e região. No Portal IG', a matéria No Brasil, 4 a cada 10 jovens perderam a renda na pandemia, uma triste constatação se pode identificar no título, de cada 10 jovens brasileiros, quatro perderam sua renda em 2020.

A matéria foi disponibilizada em 29 de agosto de 2020, momento que começava acontecer um certo relaxamento das medidas sanitárias que estavam sendo questionadas pelos setores da economia e também por parte da população. Ainda não visualizamos os possíveis efeitos de uma "segunda onda" do vírus (situando o mês de janeiro de 2021), porém, os estragos sociais da "primeira onda" se materializavam nos resultados de pesquisas como a do Conselho Nacional de Juventude

\footnotetext{
7 Disponível em: https://agenciabrasil.ebc.com.br/economia/noticia/2020-04/conselho-teme-efeitos-sociais-da-pandemia-entre-os-jovens. Acesso em: 28 jan. 2021.

8 Disponível em: https://g1.globo.com/sp/santos-regiao/noticia/2020/06/29/jovens-demitidos-na-pandemia-se-viram-nos-30-para-pagar-as-contas.ghtml. Acesso em: 28 jan. 2021.

9 Disponível em: https://economia.ig.com.br/2020-08-29/no-brasil-4-a-cada-10-jovens-perderam-a-renda-na-pandemia.html. Acesso em: 28 jan. 2021.
} 
(CONJUVE). Os jovens respondentes da pesquisa indicavam ter perda na renda familiar; aquele que conseguiu manter o emprego estava trabalhando mais horas; acreditam que uma vacina é a grande descoberta para retomada da vida; os jovens anseiam pelo convívio familiar e com os amigos; e também apontam a volta do ensino presencial como importante. Na pesquisa, um dado assustador foi a alegação dos jovens sobre o quanto foram abalados emocional e psicologicamente, sentimento de insegurança, tristeza, tédio, impaciência e ansiedade, são alguns dos resultados do período.

Fizemos, aqui, um exercício de capturar e analisar algumas reportagens (sem nos preocuparmos com cronologia) que foram identificadas no próprio cotidiano dos autores do texto, cuja temática se refere à categoria social juventude, as quais nos permitem termos alguns indicativos de como os jovens têm sido tratados.

O discurso mais habitual e recorrente em relação à temática dos jovens e a pandemia de covid-19 é o alerta de especialistas (infectologistas, epidemiologistas, virologistas etc.) quanto ao aumento de contágio do vírus entre adolescentes e jovens. A preocupação diz respeito aos jovens se tornarem vetores da transmissão do vírus. Os primeiros estudos científicos apontam que a resposta imunológica de crianças e jovens é melhor ou demonstra maior resistência, acarretando casos positivados assintomáticos e baixa letalidade.

Os jovens, à medida que circulam pelos espaços, na condição de assintomáticos, acabam por transmitir o vírus para outros grupos etários, criando um paradoxo, pois, a narrativa inicial indicava que o isolamento tem o objetivo de evitar a transmissão, porém também indicava que os jovens eram o grupo mais resistente. Logo, com o passar dos meses de isolamento, os jovens, um grupo que possui uma sociabilidade que envolve reciprocidade, contato e circulação, demonstra ser o grupo social mais afetado, desgastado com a pandemia. Ao final de 2020 e início de 2021, com o aumento do número de casos entre jovens com sintomas graves, sequelas e até óbitos, a narrativa de prevenção se volta mais intensamente contra aqueles que não seguem as restrições e recomendações sanitárias.

Em reportagem do site $\mathrm{GZH}^{10}$, do dia 4 de dezembro de 2020, intitulada Casos de coronavírus entre jovens no RS atingem maior patamar desde o início da pandemia, temos uma imagem desfocada que apresenta uma aglomeração de jovens, com copos de bebidas em mãos, nenhum deles com máscaras faciais, e, na legenda da foto, o seguinte texto: "Aglomerações se tornaram mais frequentes e isso está se refletindo em novos casos de covid-19".

A referida reportagem inicia da seguinte maneira:

O Rio Grande do Sul fechou novembro com número recorde de casos confirmados de coronavírus em um mês: 69,8 mil. Além disso, o ritmo de contágio é acelerado entre adolescentes de 15 a 19 anos e jovens entre 20 e 29 anos. Somadas, essas duas faixas etárias registraram 17 mil casos no mês passado, o maior índice desde o início da pandemia, segundo dados da Secretaria Estadual da Saúde. Isso equivale a 24\% do total de infectados, ou uma em cada quatro ocorrências no Estado. (GZH, 2020).

A reportagem apresenta dados em relação ao total de contaminação no Estado do Rio Grande do Sul, em comparação aos jovens, bem como, das taxas de letalidade, que, segundo a reportagem, apesar dos jovens representarem $24 \%$ do total de contaminados, a letalidade é bem baixa, representa 0,4\% dos óbitos provocados pela doença - o que, na opinião de um especialista (infectologista), pode ser um dos motivos dos jovens estarem se resguardando menos.

Consta também uma análise de uma psicóloga, que acredita que os meses de pandemia geraram um esgotamento, e com a flexibilização em relação à abertura de cinemas, shoppings e

10 Disponível em: https:/gauchazh.clicrbs.com.br/saude/noticia/2020/12/casos-de-coronavirus-entre-jovens-no-rs-atingem-maior-patamar-desde-o-inicio-da-pandemia-ckiaqtyv1007z017wjwbe2suf.html. Acesso em: 17 jan. 2021. 
espaços públicos e privados de lazer, as pessoas interpretaram como uma "volta à normalidade", salientando a grande necessidade dos jovens de se encontrar e terem a manutenção dos laços sociais, além da importância, neste cenário, dos jovens pensarem nos idosos e nos mais vulneráveis diante do quadro de pandemia.

A reportagem apresenta um dilema, "a adolescência [juventude] é, simultaneamente, o elo frágil (por sua fraca inserção sociológica) e o elo forte (por suas energias) do conjunto de nossas sociedades" (MORIN, 2013, p. 368). Os desafios que a sociedade moderna impõe aos jovens caracterizam incertezas sobre o futuro pessoal que remetem a iniciativas de risco e transgressão. A manifestação dos jovens durante a pandemia parece expressar a ausência do medo, um desejo de correr riscos e rebeldia. Ações que facilmente são atribuídas à juventude, significando esse elo fraco da inserção sociológica por estar em descompasso com a ordem social ou vida adulta. Entretanto, a juventude também é identificada como elo forte por poder transformar a sociedade ou manter sua reprodução. A postura corajosa representa um heroísmo que permite dar certo sentido à vida, pois, o jovem passa a ser protagonista de suas ações, ao fazer isso não se compromete com a compreensão do presente: "A experiência heroica da temporalidade é apenas uma maneira de aliviar o peso da espera e reduzir a angústia suscitada pela expectativa de um futuro ainda incerto" (FURTER, 1975, p. 71).

Reportagem com discurso muito semelhante - inclusive na imagem utilizada e legenda da imagem: jovens aglomerados, conversando e se divertindo na Rua Augusta, na capital paulista - foi veiculada pelo Portal O Globo ${ }^{11}$, em 6 de dezembro de 2020, com o título Covid-19 avança entre jovens, que já são responsáveis por $20 \%$ dos casos no Brasil.

No Portal UOL ${ }^{12}$, também no dia 6 de dezembro de 2020, no título consta: Alta incidência de covid-19 em jovens eleva tensão nas famílias, trazendo o cenário do Estado de São Paulo: "A expansão da covid-19 entre menores de 29 anos fez crescer também a tensão em famílias nas quais jovens se dividem entre a busca de diversão fora de casa e o risco de contaminar parentes ao voltar" (UOL, 2020).

A matéria apresenta que a mortalidade de jovens, em São Paulo, até aquele momento, representava menos de $2 \%$ dentro dessa faixa etária, além de expor diálogos que evidenciam conflitos entre jovens e seus pais quanto a saírem para se divertir com amigos e amigas, e os cuidados que pais e avós estão tendo na tentativa de manter o isolamento social, a fim de mitigar as possibilidades de contaminação de covid-19. Na reportagem, que procura demonstrar tanto jovens que vêm saindo como jovens que têm mantido isolamento, aparecem situações como essa relatada abaixo, que mostra a preocupação da jovem com sua família e entorno, destoando da ideia generalista que costumamos ter quanto aos jovens:

"Fiquei muito irritada porque vi amigos indo para festas com 40 pessoas, no auge da pandemia, e postando nas redes sociais", diz a jovem, que fala em "decepção" e avalia ter se afastado de algumas pessoas com quem mantinha contato virtual "pelo bem da saúde mental". (UOL, 2020).

Quando pensamos nos jovens como categoria social, destacamos a juventude no plural, fato que permite perceber um grupo heterogêneo com valores e interesses diversos. O cuidado que a referida matéria apresenta, está orientada para a percepção de que, embora nas narrativas de senso comum explicitem o contrário (despreocupação, irresponsabilidade, individualismo, descuido etc.), parte dos jovens respeita as orientações sanitárias e demonstra preocupação com familiares e amigos pertencentes ou não ao grupo de risco.

11 Disponível em: https://oglobo.globo.com/sociedade/coronavirus/covid-19-avanca-entre-jovens-que-ja-sao-responsaveis-por-20-dos-casos-no-brasil-24782477. Acesso em: 17 jan. 2021

12 Disponível em: https://noticias.uol.com.br/ultimas-noticias/agencia-estado/2020/12/06/alta-incidencia-de-covid-em-jovens-eleva-tensao-nas-familias.htm. Acesso em: 17 jan. 2021. 
A inesperada pandemia, além de promover transformações de diferentes ordens, ao passo que ia ganhando magnitude, lamentavelmente promovia mudanças no modus vivendi da juventude, conforme apresentado na matéria intitulada: Jovens relatam mudanças de rotina e de humor em estudo sobre pandemia apresentada no jornal Correio do Povo ${ }^{13}$, do dia 1 de dezembro de 2020. Com base no conteúdo veiculado, a pandemia e seus desdobramentos desencadearam significativas "[...] mudanças de rotina, alterações de humor, piora na saúde e adoção de hábitos alimentares não saudáveis" (CORREIO DO POVO, 2020), na vida de cerca de $50 \%$ dos jovens entrevistados. O impacto teve forte correlação com as variáveis gênero e idade, de modo que no grupo das jovens entrevistadas, o percentual "[...] sobe para $61,6 \%$. No recorte por idade, o índice é maior entre adolescentes mais velhos, de 16 e 17 anos. Nessa faixa etária, tais sentimentos foram relatados por $55,3 \%$, percentual superior aos $45,5 \%$ registrados no grupo entre 12 e 15 anos" (CORREIO DO POVO, 2020). Nota-se que ser mulher e pertencer ao grupo dos "adolescentes" mais velhos num contexto de pandemia, além do risco de contrair covid-19, o cenário desencadeia também impactos de diferentes ordens.

A soma de contaminados e de mortos pela covid-19, além de expressar indicadores que revelam a letalidade do vírus que promoveu a maior tragédia da história mundial e brasileira, lamentavelmente expõe ações individualizadas e de grupos de pessoas que ajudam na disseminação do vírus e na banalização das medidas preventivas. A matéria apresentada no portal $\mathrm{UOL}^{14}$ do dia 12/12/2020 e nomeada: Jovens ignoram covid-19 e lotam bares em SP: 'A gente já meteu o louco' é um indicativo de como a pandemia tem sido considerada por alguns jovens.

A reportagem foi publicizada num dia em que a taxa de mortes chegou a 697 vítimas e 52.000 casos positivos de covid-19 em 24 horas. Nota-se que nem mesmo um cenário marcado por tantas perdas e contaminações foi capaz de despertar o desejo de cuidar de si mesmo e, sobretudo de pensar coletivamente, o que ficou evidente na fala de alguns jovens que foram entrevistados: "As pessoas estão cansadas. Começou essa birosca dia 15 de março [2020]. Já é 12 de dezembro [2020], ninguém aguenta mais" (UOL, 2020). Temos a impressão de que o olhar generalizante e o suposto "negacionismo" afetaram drasticamente a capacidade de ver e compreender a gravidade da situação: "Não tenho medo. Dizem que A+ [tipo sanguíneo] não pega e eu sou A+" (UOL, 2020). É possível perceber que o negacionismo é fundamente em percepções sem senso de nada, mas que promove um impacto sem medidas na prevenção e contenção do vírus.

A matéria teve como recorte a fala de alguns jovens frequentadores de um bar em São Paulo, portanto, ela não representa a juventude como um todo. No entanto, o cenário apresentado oferece pistas de como pode ser arriscado tratar uma pandemia como sendo um acontecimento "normal" e que essa falsa sensação de normalidade poderá resultar num duplo processo. Por um lado, o suposto empoderamento daqueles que banalizam as medidas preventivas, por outro, a capacidade de desmotivar aqueles que sempre cuidaram de si mesmos e dos outros.

É inegável que o desdobramento da pandemia tem produzido incertezas, algumas com impacto no presente, enquanto outras comprometem a perspectiva de futuro, o vir a ser. Quando consideramos a ideia de juventude na sua pluralidade, notamos que grande parte dos jovens brasileiros não tem muitas certezas sobre o futuro, dadas as condições de precariedade que muitos são submetidos. Não por acaso, a verticalização dos estudos se torna para muitos a única forma de projeção social e melhoria de vida. Alçar níveis mais elevados de escolaridade passa a ser uma forma de tentar driblar possíveis desclassificações futuras decorrentes da ausência de títulos escolares que os diferentes mercados exigem.

13 Disponível em: https://bellamais.correiodopovo.com.br/relacionamentos/filhos/jovens-relatam-mudan\%C3\%A7as-de-rotina-e-de-humor-em-estudo-sobre-pandemia-1.530600. Acesso em: 17 jan. 2021.

14 Disponível em: https://noticias.uol.com.br/cotidiano/ultimas-noticias/2020/12/12/jovens-se-aglomeram-em-bares-de-sp-a-gente-ja-meteu-o-louco.htm. Acesso em: 17 jan. 2021. 
Num cenário atípico como o de uma pandemia que persiste, a permanência nos diferentes ciclos de ensino deveria ser uma das principais apostas para assegurar possibilidades no presente e no futuro. No entanto, a matéria intitulada: № de alunos que abandonam faculdade deve subir após a pandemia, e setores poderão enfrentar falta de mão de obra, apresentada no Portal do G1 ${ }^{15}$ do dia 13 de setembro de 2020, lamentavelmente apresenta outra realidade.

Nota-se que a adesão e permanência de muitos jovens nas instituições de ensino privado foi drasticamente comprometida nos últimos tempos, conforme apresentado na reportagem: "[...] o número de novos alunos no segundo semestre de 2020 também sofreu redução, de 50\%, segundo o sindicato das mantenedoras do ensino superior. O motivo? Desemprego e perda de poder aquisitivo dos alunos ou familiares". O impacto dos desdobramentos da pandemia tem obrigado familiares e estudantes a fazerem escolhas e num contexto de redução de recursos financeiros, a prioridade acaba sendo o atendimento das necessidades de sobrevivência. A reportagem revela também que “[...] a taxa de inadimplência aumentou 51\%, se comparado ao mesmo período do ano anterior e a evasão cresceu 14\%”. A ideia meritocrática de que todos podem participar da mesma competição em busca dos títulos escolares e de posições sociais, independente de sua origem social, mais do que em outros momentos, tem sido desconstruída. Se em tempos de "normalidade" a esfera social se constitui numa arena onde muitos jovens precisam traçar estratégias para melhor salvaguardar sua posição social, em tempos de pandemia, o número de exigências se torna muito maior, com dificuldades e restrições maiores.

No portal El País Brasil ${ }^{16}$, no dia 5 de dezembro de 2020, temos uma matéria intitulada Os jovens da América Latina erguem sua voz, iniciando com uma grande imagem de jovens peruanos, de Lima, todos de máscara facial, protestando por questões políticas e sanitárias, com o seguinte depoimento de uma estudante universitária: "Estava cansada de tudo o que estava acontecendo. É impossível que estas pessoas que estão aqui [os congressistas] em vez de tomarem decisões pensando no bem-estar da população, ajam pensando nos seus próprios bolsos, em lucrar" (EL PAÍS BRASIL, 2020).

De maneira geral, o texto comenta quanto à situação dos jovens protestando recentemente no Peru, no Chile, Colômbia e Equador, enfatizando a dimensão geracional e de ativismo político de diferentes causas:

As reivindicações são muito variadas e respondem às urgências de cada país. Às vezes respaldam a pauta de outros grupos, como a dos povos indígenas no Equador. Entretanto, há um denominador comum: o fator geracional, acompanhado das ferramentas e códigos de comunicação habituais entre os jovens. Por exemplo, o uso das redes sociais. Os manifestantes recorrem a elas para se congregarem, se organizarem, ajudarem os feridos e procurarem os desaparecidos durante as manifestações. Também para lançar suas reivindicações e documentar as marchas através de canais criados por eles mesmos em plataformas como Instagram, Facebook e TikTok, onde desafiam a narrativa da mídia tradicional quando consideram que esta não reflete seu ponto de vista. (EL PAÎ́S BRASIL, 2020).

A matéria reforça a ideia de que as ações perpetradas pelos jovens continuam existindo, o que exige a ressignificação de certos discursos que negam a existência do protagonismo juvenil, enquanto grupo organizado que promove ativismo político em prol de diferentes causas e transformações na esfera social.

15 Disponível em: https://g1.globo.com/educacao/noticia/2020/09/13/no-de-alunos-que-abandonam-faculdade-deve-subir-aposa-pandemia-e-setores-poderao-enfrentar-falta-de-mao-de-obra.ghtml. Acesso em: 12 jan. 2021.

16 Disponível em: https://brasil.elpais.com/internacional/2020-12-05/os-jovens-da-america-latina-erguem-sua-voz.html. Acesso em: 17 jan. 2021. 
A mobilização dos jovens em diferentes países da América Latina é um indicativo de que é possível construir um "vir a ser", um mundo novo, mas que, para tanto, o despertar precisa atingir a juventude em diferentes partes do mundo.

Os profissionais da educação, mais precisamente quem trabalha com ensino médio, certamente sabe o quão significativa é a carga de conformismo que alguns jovens apresentam ao chegar no último ciclo da escola básica. Não por acaso, o ensino médio, a etapa que mais concentra jovens, constituiu-se no gargalo da educação pública no Brasil. Os indicadores de abandono, repetência e distorção idade-série aludem a um modelo de escola pouco atrativo.

Ao retomar a dinâmica da historicidade, Valle (2014) destaca que a escola tem sido convocada a corresponder às múltiplas apostas da modernidade e tempos seguintes. No entanto, a guerra ideológica amplamente difundida contra a educação, além de beneficiar apenas alguns interesses políticos, lamentavelmente tem contribuído para que os sistemas de ensino direcionem o potencial dos jovens para a superação dos exames vestibulares, de modo a aceitar com certa dose de conformismo um lugar bem demarcado na esfera social.

\section{Considerações finais}

Neste ensaio, ao trazermos materiais jornalísticos que estão disponíveis na internet e que tematizam de maneira diversa as juventudes, especialmente a brasileira, pudemos visualizar a produção sociológica referente à chamada "Sociologia da Juventude" como chave de leitura para pensar quanto ao contexto pandêmico atual e a situação dos jovens nessas informações produzidas e veiculadas para a população em geral.

A diversidade de aspectos aos quais os jovens são correlacionados evidencia que se trata de uma categoria social que ganha destaque no contexto atual, porque a partir das culturas juvenis, suas interações e contextos, a mídia produz conteúdos que explicitam problemáticas, representações e contextualizações quanto à família, relações, instituições, mundo do trabalho, experiências, expectativas etc.

Observar e analisar atentamente o que é produzido pela mídia nos ajuda a compreender discursos que legitimam fatos, contextos e opiniões das mais diversas, e que, neste caso da situação dos jovens na pandemia, manifestaram-se em múltiplas formas: desde o senso comum (quanto ao individualismo, despreocupação e irresponsabilidade dos jovens), passando por discursos que manifestaram preocupação quanto aos jovens (exposição ao vírus, implicações pessoais e coletivas, aspectos educativos/formativos, mundo do trabalho etc.).

Compreender esse contexto difícil gerado pela pandemia, focando o olhar quanto à experiência dos jovens nesse cenário - mas não se restringindo às análises apenas de psicólogos, infectologistas, virologistas e epidemiologistas, profissionais identificados com suas opiniões nas reportagens utilizadas - é papel dos professores e professoras que têm o compromisso com a formação dessa geração, mergulhando em seus microcosmos e aproveitando todo desvelamento do mundo social que a pandemia nos traz (principalmente quanto às desigualdades sociais no Brasil), que impactam fortemente jovens e sua possibilidade de futuro. Precisamos, mais ainda, compreender todo esse cenário para que as questões educativas e pedagógicas sejam potencializadoras, e, nesse aspecto, acreditamos que o conjunto de informações identificadas nos veículos midiáticos aqui utilizadas fornecem um retrato interessante e amplo do tempo presente. 


\section{Referências}

ALMEIDA, Maria Isabel Mendes de; EUGENIO, Fernanda (org.). Culturas Jovens: novos mapas do afeto. Rio de Janeiro: Jorge Zahar, 2006.

ARROYO, Lorena; MANETTO, Francesco. Os jovens da América Latina erguem sua voz. El País Brasil, Cidade do México, 05 dez. 2020. Disponível em: https://brasil.elpais.com/internacional/2020-12-05/os-jovens-da-america-latina-erguem-sua-voz.html. Acesso em: 17 jan. 2021.

BAUMAN, Zygmunt. Sobre educação e juventude: conversas com Ricardo Mazzeo. Rio de Janeiro: Zahar, 2013.

BOURDIEU, Pierre. A “juventude” é apenas uma palavra. In: BOURDIEU, Pierre. Questões de sociologia. Rio de Janeiro: Marco Zero, 1983. p. 112-121.

BOURDIEU, Pierre. A distinção: crítica social do julgamento. Tradução Daniela Kern e Guilherme J. F. Teixeira. São Paulo: Edusp; Porto Alegre: Zouk, 2007.

DAYRELL, Juarez. O jovem como sujeito social. Revista Brasileira de Educação, Rio de Janeiro, n. 24, p. 40-52, set./dez. 2003. Disponível em: https://www.scielo.br/pdf/rbedu/n24/n24a04. Acesso em: 29 ago. 2020.

FORACCHI, Marialice Mencarini. A juventude na sociedade moderna. São Paulo: Editora da Universidade de São Paulo, 2018.

FRAZÃO, Fernão. No Brasil, 4 a cada 10 jovens perderam a renda na pandemia. IG ECONOMIA, 29 ago. 2020. Disponível em: https://economia.ig.com.br/2020-08-29/no-brasil-4-a-cada-10-jovens-perderam-a-renda-na-pandemia. html. Acesso em: 28 jan. 2021.

FURTER, Pierre. Juventude e tempo presente: fundamentos de uma pedagogia. Petrópolis: Vozes, 1975.

GROPPO, Luís Antônio. Juventude: ensaios sobre sociologia e história das juventudes modernas. Rio de Janeiro: DIFEL, 2000.

GROPPO, Luís Antônio. Sentidos de juventude na sociologia e nas políticas públicas do Brasil contemporâneo. Revista de Políticas Públicas, São Luís, v. 20, n. 1, p. 383-402, jan./jun. 2016. Disponível em: http://www.periodicoseletronicos. ufma.br/index.php/rppublica/article/view/5062. Acesso em: 29 ago. 2020.

GROPPO, Luís Antônio. Introdução à Sociologia da Juventude. Jundiaí: Paco Editorial, 2017.

GROPPO, Luís Antônio; SILVEIRA, Isabella Batista. Juventude, classe social e política: reflexões teóricas inspiradas pelo movimento das ocupações estudantis no Brasil. Argumentum, Vitória, v. 12, n. 1, p. 7-21, jan./abr. 2020. Disponível em: https://periodicos.ufes.br/argumentum/article/view/30125. Acesso em: 29 ago. 2020.

JOVENS relatam mudanças de rotina e de humor em estudo sobre pandemia. Bellamais Correio do Povo, Porto Alegre, 01 dez. 2020. Disponível em: https://bellamais.correiodopovo.com.br/relacionamentos/filhos/jovens-relatam mudan\%C3\%A7as-de-rotina-e-de-humor-em-estudo-sobre-pandemia- 1.530600. Acesso em: 17 jan. 2021.

KEHL, Maria Rita. A juventude como sintoma da cultura. In: NOVAES, Regina; VANNUCHI, Paulo. Juventude e sociedade: trabalho, educação, cultura e participação. São Paulo: Instituto Cidadania: Editora Fundação Perseu Abramo, 2003. p. 89-114.

KER, João; MARQUES, Julia. Alta incidência de Covid-19 em jovens eleva tensão nas famílias. UOL, São Paulo, 06 dez. 2020. Disponível em: https://noticias.uol.com.br/ultimas-noticias/agencia-estado/2020/12/06/alta-incidencia-de-covid-em-jovens-eleva-tensao-nas-familias.htm. Acesso em: 17 jan. 2021.

LIMA, Isabella. Jovens demitidos na pandemia 'se viram nos 30' para pagar as contas. G1, Santos, 29 jun. 2020. Disponível em: https:/g1.globo.com/sp/santos-regiao/noticia/2020/06/29/jovens-demitidos-na-pandemia-se-viram-nos-30-para-pagar-as-contas.ghtml. Acesso em: 28 jan. 2021.

MARGULIS, Mario; URRESTI, Marcelo. La juventud es más que una palabra. In: MARGULIS, Mario; URRESTI, Marcelo (org.) La juventud es Más Que una Palabra. Buenos Aires: Biblos, 1996. p. 1-13.

MARIZ, Renata. COVID-19 avança entre jovens que já são responsáveis por 20\% dos casos no Brasil. O Globo, Rio de Janeiro, 06 dez. 2020. Disponível em: https://oglobo.globo.com/sociedade/coronavirus/covid-19-avanca-entre-jovens-que-ja-sao-responsaveis-por-20-dos-casos-no-brasil-24782477. Acesso em: 17 jan. 2021.

MARTINHO, Anahi. Jovens ignoram Covid-19 e lotam bares em SP: 'a gente já meteu o louco'. UOL, São Paulo, 12 dez. 2020. Disponível em: https://noticias.uol.com.br/cotidiano/ultimas-noticias/2020/12/12/jovens-se-aglomeram-em-bares-de-sp-a-gente-ja-meteu-o-louco.htm. Acesso em: 17 jan. 2021. 
MORIN, Edgar. A adolescência. In: MORIN, Edgar. A via para o futuro da humanidade. Rio de Janeiro: Bertrand Brasil, 2013.

OLIVEIRA, Elida. No de alunos que abandonam faculdade deve subir após a pandemia, e setores poderão enfrentar falta de mão de obra. G1, 13 set. 2020. Disponível em: https:/g1.globo.com/educacao/noticia/2020/09/13/no-de-alunos-que-abandonam-faculdade-deve-subir-apos-a-pandemia-e-setores-poderao-enfrentar-falta-de-mao-de-obra. ghtml. Acesso em: 12 jan. 2021.

ORTEGA Y GASSET, Jose. Juventude. In: ORTEGA Y GASSET, Jose. A rebelião das massas. [S.l.]: Ed. Ridendo Castigat Mores, 2005. E-book. Disponível em: http://www.ebooksbrasil.org/adobeebook/ortega.pdf. Acesso em: 2 jan. 2021.

PAIS, José Machado. Ganchos, tachos e biscates: jovens, trabalho e futuro. Porto: Ambar, 2001.

RIBEIRO, Darcy. O povo brasileiro: a formação e o sentido do Brasil. São Paulo: Companhia das Letras, 2006.

RODRIGUES, Alex. Conselho teme efeitos sociais da pandemia entre os jovens. Agência Brasil, Brasília, 16 abr. 2020. Disponível em: https://agenciabrasil.ebc.com.br/economia/noticia/2020-04/conselho-teme-efeitos-sociais-da-pandemia-entre-os-jovens. Acesso em: 28 jan. 2021.

SANTOS, Otávio Maia dos et al. Fakenews na pandemia da COVID-19: um desserviço à sociedade brasileira. Cenas Educacionais, Bahia, v. 3, n. e9300, p. 1-16, 2020. Disponível em: https://www.revistas.uneb.br/index.php/cenaseducacionais/article/view/9300. Acesso em: 16 jan. 2021.

SAVAGE, Jon. A criação da juventude: como o conceito de teenage revolucionou o século XX. Rio de Janeiro: Rocco, 2009.

SETTON, Maria da Graça. Mídia e educação. São Paulo: Contexto, 2010.

SOARES, Fernando. Casos de coronavírus entre jovens no RS atingem maior patamar desde o início da pandemia. Gaúcha ZH, Porto Alegre, 04 dez. 2020. Disponível em: https://gauchazh.clicrbs.com.br/saude/noticia/2020/12/casos-de-coronavirus-entre-jovens-no-rs-atingem-maior-patamar-desde-o-inicio-da-pandemia-ckiaqtyv1007z017wjwbe2suf. html. Acesso em: 17 jan. 2021.

THOMPSON, John Brookshire. A mídia e a modernidade: uma teoria social da mídia. 8. ed. Petrópolis: Vozes, 1998.

VALLE, Ione Ribeiro. O lugar da educação nos projetos de modernidade: escola e diferenciação social. In: VALLE, Ione Ribeiro. Moderno, modernidade e modernização: a educação nos projetos de Brasil. Séculos XIX e XX. Belo Horizonte: Mazda, 2014. p. 17-34.

VELHO, Gilberto. Juventudes, projetos e trajetórias na sociedade contemporânea. In: ALMEIDA, Maria Isabel Mendes de; EUGENIO, Fernanda (org.). Culturas jovens: novos mapas de afeto. Rio de Janeiro: Jorge Zahar, 2006. p. 192-200.

WEISHEIMER, Nilson et al. A construção social da juventude. In: WEISHEIMER, Nilson et al. Sociologia da juventude. Curitiba: InterSaberes, 2013. p. 13-30.

Data de submissão: 31/01/2021

Data de aceite: $02 / 02 / 2021$ 